\title{
Esterilização de farinha de subprodutos animais em esterilizador industrial
}

\author{
Industrial sterilization of animal meal
}

\author{
Marcio Antônio MAZUTTI ${ }^{1 *}$, Helen TREICHEL ${ }^{2}$, Marco Di LUCCIO²
}

\begin{abstract}
Resumo
As farinhas de subprodutos animais se apresentam como uma fonte praticamente completa da maioria dos aminoácidos requeridos para uma alimentação equilibrada. Estas farinhas são amplamente usadas para corrigir as deficiências nutricionais, que ocorrem em outras matériasprimas para rações, como os farelos de origem vegetal. No entanto, constituem um ambiente favorável à proliferação de microrganismos, tanto durante o processamento quanto na estocagem. A Portaria SARC 002 de 13/02/2003 no Anexo I da Instrução Normativa Número 15 do Ministério da Agricultura, Pecuária e Abastecimento propõe que a etapa de esterilização das farinhas poderá ser realizada antes do processo de cocção dos subprodutos ou na própria farinha, contanto que seja empregado vapor saturado direto a uma temperatura mínima de $133^{\circ} \mathrm{C}$ por um tempo mínimo de 20 minutos. Industrialmente, o que se deseja é obter um produto final com padrões higiênicos sanitários aceitáveis, com teor proteico o mais alto possível. Nesse sentido, o objetivo deste trabalho foi investigar diferentes estratégias de processamento da farinha de subprodutos de indústria de aves, observando aquela mais eficiente para a esterilização: se no subproduto antes da digestão ou se na própria farinha. Foram realizados testes em escala piloto com capacidade para $150 \mathrm{~kg}$ e em escala industrial com capacidade de $3.000 \mathrm{~kg}$. O processo de esterilização em escala industrial apresentou um melhor desempenho comparado com o processo piloto. O teor de proteína aumentou em todos os testes e a digestibilidade final da farinha foi de aproximadamente $92 \%$, o que eleva seu valor de mercado. Com relação à eliminação de microrganismos, o processo industrial foi eficiente, uma vez que não foi verificada contagem em nenhum dos três testes realizados.
\end{abstract}

Palavras-chave: farinha de subprodutos; esterilização; subprodutos de frango.

\begin{abstract}
Animal meal obtained from animal offal offers a fairly complete source of most of the aminoacids required for a balanced animal diet. These products are used to correct nutritional deficiencies of other foodstuffs used in animal feed, such as vegetable feeds. However, animal meal is a good source for microorganism growth during processing or storage. A government regulation proposes that a stage of feed sterilization could be carried out before cooking the animal byproducts (offal, feathers, etc.) or even of the meal itself, considering that if direct saturated steam is used, the minimum temperature should be $133^{\circ} \mathrm{C}$, for a minimum of 20 minutes, or if dry heat is used the meal should be exposed to a dry heat of $140^{\circ} \mathrm{C}$ for a minimum of 3 hours. In industry, a final product that meets both the sanitary standards and high protein content is required. In this context, this work aimed to study different strategies for processing meal prepared from byproducts of poultry slaughterhouses, searching for the most effective technique for sterilization: whether pre-digestion or sterilization of the meal itself. Industrial (3,000 kg) and pilot $(150 \mathrm{~kg}$ ) plant tests were carried out. Sterilization on an industrial scale presented a better performance than the pilot plant tests. Protein content increased in all tests and the final digestibility of the meal was approximately 92 per cent, which increases its final market value. The industrial process was effective removing microorganisms, since no count was detected in the meal after any of the tests.

Keywords: animal byproduct meal; sterilization; poultry by-products.
\end{abstract}

\section{Introdução}

As farinhas de subprodutos animais podem ser definidas como um produto não comestível resultante do processamento de resíduos de animais que atenda ao padrão de qualidade em relação a aspectos higiênico-sanitários e nutricionais (BELLAVER, 2005). Estas farinhas são consideradas fontes completas de praticamente todos os aminoácidos (essenciais ou não essenciais) requeridos para uma alimentação racional, sendo usadas para corrigir as deficiências de alguns aminoácidos, que ocorrem em outras matérias-primas para rações, como os farelos de origem vegetal (RITTNER, 2001). A caracterização detalhada de todas as farinhas animais pode ser encontrada no Compêndio Brasileiro para Alimentação Animal (BRASIL, 2005).

O processo básico de produção de farinhas animais consiste na retirada dos excessos de água, trituração dos resíduos não comestíveis de matança para tamanho menor que $5 \mathrm{~cm}$, quando isso for necessário devido ao tamanho das partes a processar, e digestão com ou sem pressão, por

Recebido para publicação em 15/1/2008

Aceito para publicação em 8/9/2008 (003137)

${ }^{1}$ Faculdade de Engenharia de Alimentos - FEA, Universidade Estadual de Campinas - UNICAMP, Rua Monteiro Lobato, 80, CEP 13083-862, Campinas - SP, Brasil,

E-mail:marciom@fea.unicamp.br

${ }^{2}$ Departamento de Engenharia de Alimentos, Universidade Regional Integrada do Alto Uruguai e das Missões Campus de Erechim, Av. 7 de Setembro, 1621, CEP 99700-000, Erechim - RS, Brasil

${ }^{*}$ A quem a correspondência deve ser enviada 
tempo variável dependendo do processo. A gordura é então drenada, prensada ou centrifugada e o resíduo sólido é moído na forma de farinha (máximo de $10 \%$ de retenção em peneira de 1,68 cm) com especificações de granulometria variáveis. As principais variáveis que afetam a qualidade das farinhas são: a) umidade: sendo superior a $8 \%$ pode facilitar a contaminação bacteriana e suas consequências, e umidade muito baixa pode indicar a queima do ingrediente no processo. A queima pode estar ainda associada ao desgaste do equipamento, excessivo tempo de retenção e/ou mau funcionamento de manômetros e termômetros; b) textura: na composição da farinha, entram em quantidades variáveis os ossos, que são de difícil trituração, mas que podem ser segregados em pedaços maiores para remoagem e manutenção de granulometria adequada. A granulometria ideal seria sem retenção em peneira Tyler $6(3,36 \mathrm{~mm})$, no máximo $3 \%$ de retenção em Tyler 8 (2,38 mm) e no máximo $10 \%$ de retenção na peneira Tyler 10 (1,68 mm); c) contaminações no processo (sangue, penas, resíduos de incubatório, cascos, chifres, pelos, conteúdo digestivo) devem ser minimizadas em função da definição de cada produto e da manutenção dos padrões de qualidade e reprodutibilidade; e) o tempo entre o abate e o processamento está se tornando muito importante devido ao aparecimento de novos processadores independentes. O processamento deve ser feito preferencialmente em seguida ao abate ou sempre dentro das 24 horas seguintes ao abate, evitando assim a putrefação e oxidação das gorduras (BELLAVER, 2005; MAPA, 2003).

As farinhas de subprodutos constituem um ambiente favorável à proliferação de microrganismos, tanto durante a etapa de processamento quanto na etapa de armazenamento. Uma farinha de subprodutos é dita com qualidade higiênicosanitária adequada quando todas as operações de processamento, incluindo o acondicionamento, são realizadas sem demoras inúteis e em condições que excluam contaminação, deterioração e proliferação de microrganismos. Para que uma farinha de subprodutos atenda aos padrões higiênicos sanitários ela deve apresentar, após o processo de esterilização, a ausência de contagem de bactérias patogênicas (ausência de Salmonella sp. em $25 \mathrm{~g}$ ) e esporos (ausência de Clostridium perfringens em $1 \mathrm{~g}$ de produto) (MAPA, 2003).

A Portaria SARC 002 de 13/02/2003 no Anexo I da Instrução Normativa Número 15 do Ministério da Agricultura, Pecuária e Abastecimento (MAPA, 2003), regulamentou que a etapa de esterilização pode ser realizada antes do processo de cocção dos subprodutos ou na própria farinha, desde que seja empregado vapor saturado direto a uma temperatura mínima de $133^{\circ} \mathrm{C}$ por um tempo mínimo de 20 minutos. Industrialmente, o que se deseja é obter um produto final com padrões higiênicos sanitários aceitáveis, com teor proteico o mais alto possível. No entanto, durante o processamento térmico pode ocorrer a degradação de proteínas e outros componentes, levando à perda de qualidade do produto. O correto controle do tempo e da temperatura de processamento exerce uma grande influência na qualidade final do produto (RITTNER, 2001; MANN, 1962).

Nesse sentido, o objetivo deste trabalho foi investigar diferentes estratégias de processamento da farinha de subprodutos de indústria de aves, observando a mais eficiente para a esterilização: se no subproduto antes da digestão ou se na própria farinha. Além disso, o trabalho se propôs a acompanhar o processo de esterilização num esterilizador batelada em escala industrial, com capacidade de $3.000 \mathrm{~L}$.

\section{Material e métodos}

\subsection{Matéria-prima e equipamentos}

Os subprodutos in natura utilizados para os testes de esterilização foram constituídos de vísceras e carcaças de frangos provenientes de um frigorífico local. A farinha obtida da mesma matéria-prima de aves utilizada nos testes de esterilização era proveniente do mesmo frigorífico. O processo de esterilização foi realizado em duas etapas. Na primeira etapa, foi acompanhada a esterilização de subprodutos in natura e em farinha de subprodutos em um esterilizador batelada vertical, em escala piloto, com capacidade útil de $150 \mathrm{~kg}$. Na segunda etapa, foi acompanhada a esterilização em farinha de subprodutos em um esterilizador batelada horizontal em escala industrial com capacidade útil de $3.000 \mathrm{~kg}$. O esterilizador piloto é encamisado, com injeção direta de vapor na massa e não possui agitação interna. O esterilizador industrial é encamisado, com injeção de vapor saturado na massa. Além disso, apresenta dispositivo de agitação interna com injeção de vapor saturado na camisa, nos eixos e nas pás de agitação.

A matéria-prima usada em cada esterilizador era proveniente do mesmo lote. Assim, foi possível avaliar e comparar a termo-resistência para cada tipo de esterilizador, uma vez que é possível haver diferenças na termo-resistência quando lotes diferentes são usados.

\subsection{Procedimento experimental para a esterilização}

O esterilizador foi carregado conforme especificado a seguir, sendo monitoradas as pressões do vapor na camisa e na massa a ser esterilizada até que fossem atingidos $133^{\circ} \mathrm{C}$, mantendo-se por 20 minutos nesta temperatura. As condições de temperatura e pressão de esterilização sugeridas na Instrução Normativa foram baseadas na Norma Europeia, nas quais se tem por objetivo a redução do risco de contaminação pela BSE. Para a grande maioria dos microrganismos, temperaturas e pressões menores seriam suficientes para a esterilização.

\section{Esterilização em escala piloto}

O esterilizador piloto era carregado com $130 \mathrm{~kg}$ de farinha ou subprodutos in natura em cada teste. A Tabela 1 apresenta um resumo dos parâmetros avaliados na esterilização de subprodutos in natura e em forma de farinha na unidade piloto. Em todos os testes, foi verificada a influência da manipulação da pressão do vapor com relação ao tempo de aquecimento necessário para atingir a temperatura de $133{ }^{\circ} \mathrm{C}$, além da eficiência na eliminação de microrganismos e manutenção das características nutricionais após o processo.

Para a esterilização em subprodutos in natura, foram realizados quatro testes. Nos testes 1 e 2 , a pressão interna e a pressão na camisa do esterilizador mantiveram-se constantes 
Tabela 1. Parâmetros Avaliados nos testes de esterilização de subprodutos in natura e em farinha de subprodutos.

\begin{tabular}{ccccc}
\hline Testes & $\begin{array}{c}\text { Pressão } \\
\text { interna } \\
\left(\mathrm{kgf.cm}^{-2}\right)\end{array}$ & $\begin{array}{c}\text { Pressão na } \\
\text { camisa } \\
\left(\mathrm{kgf.cm}^{-2}\right)\end{array}$ & $\begin{array}{c}\text { Tempo de } \\
\text { aquecimento } \\
(\text { minutos })\end{array}$ & $\begin{array}{c}\text { Adição de } \\
\text { água (\%) }\end{array}$ \\
\hline \multicolumn{5}{c}{ Esterilização de subprodutos in natura } \\
1 & 2,5 & 7,5 & 35,0 & 0,0 \\
2 & 2,5 & 7,5 & 38,0 & 0,0 \\
3 & $5,5-2,5$ & 7,5 & 47,0 & 0,0 \\
4 & $5,5-2,5$ & $7,5-3,0$ & 34,0 & 0,0 \\
1 & $5,5-2,5$ & 7,6 & 23,0 & 0,0 \\
2 & $3,5-2,2$ & $7,8-0,0$ & 22,4 & 0,0 \\
3 & $5,0-2,2$ & $7,8-0,0$ & 22,0 & 14,0 \\
\hline \multicolumn{5}{c}{}
\end{tabular}

durante todo o processo. No teste 3 a pressão interna foi mantida em $5,5 \mathrm{kgf} . \mathrm{cm}^{-2}$ até atingir a temperatura de esterilização $\left(133^{\circ} \mathrm{C}\right)$ e durante a esterilização foi baixada para $2,5 \mathrm{kgf} . \mathrm{cm}^{-2}$. A pressão na camisa foi mantida constante. No teste 4 a pressão interna foi ajustada da mesma maneira que no teste 3 , porém a pressão na camisa após atingir a temperatura de esterilização foi diminuída de 7,5 kgf.cm ${ }^{-2}$ para 3,0 kgf.cm ${ }^{-2}$. Em nenhum teste foi adicionada água durante o processo de esterilização.

Para a esterilização de farinha de subprodutos foram realizados 3 testes. No teste 1 a pressão interna, após atingir a temperatura de esterilização, foi reduzida de $5,5 \mathrm{kgf}_{\mathrm{cm}} \mathrm{cm}^{-2}$ para $2,5 \mathrm{kgf.cm}^{-2}$, e a pressão na camisa do esterilizador mantevese constante durante todo o processo. No teste 2 a pressão interna, após atingir a temperatura de esterilização, foi reduzida de $3,5 \mathrm{kgf.} \mathrm{cm}^{-2}$ para 2,2 $\mathrm{kgf.cm}{ }^{-2}$ e a camisa do esterilizador despressurizada completamente. No teste 3 a pressão interna foi reduzida de 5,0 kgf.cm ${ }^{-2}$ para 2,2 kgf. $\mathrm{cm}^{-2}$ e a camisa do esterilizador, despressurizada completamente. $\mathrm{O}$ teste 3 apresenta a adição de $14 \%$ p/p de água na farinha.

\section{Esterilização em escala industrial}

Foram realizados três testes de esterilização em farinha de subprodutos no esterilizador escala industrial. O esterilizador era carregado com $2.400 \mathrm{~kg}$ de farinha em cada teste. A Tabela 2 apresenta um resumo dos parâmetros avaliados durante a esterilização de farinha de subprodutos em escala industrial. No teste 1, a pressão interna, após atingir a temperatura de esterilização, foi reduzida de $5,5 \mathrm{kgf} . \mathrm{cm}^{-2}$ para $2,5 \mathrm{kgf} . \mathrm{cm}^{-2}$, e a pressão na camisa do esterilizador manteve-se constante durante todo o processo. No teste 2, a pressão interna, após atingir a temperatura de esterilização, foi reduzida de $3,5 \mathrm{kgf.cm}^{-2}$ para $2,2 \mathrm{kgf.cm}{ }^{-2}$ e a camisa do esterilizador, despressurizada completamente. No teste 3 , a pressão interna, após atingir a temperatura de esterilização, foi reduzida de $5,0 \mathrm{kgf} . \mathrm{cm}^{-2}$ para $2,2 \mathrm{kgf} . \mathrm{cm}^{-2}$ e a camisa do esterilizador, despressurizada completamente.

\subsection{Métodos analíticos}

Os produtos processados foram analisados em: de gordura, proteína total, proteína digestível, umidade, cinzas, fósforo e
Tabela 2. Parâmetros Avaliados na Esterilização de farinha de subprodutos em esterilizador industrial.

\begin{tabular}{ccccc}
\hline Testes & $\begin{array}{c}\text { Pressão } \\
\text { interna } \\
\left(\mathrm{kgf.cm}^{-2}\right)\end{array}$ & $\begin{array}{c}\text { Pressão na } \\
\text { camisa } \\
\left(\mathrm{kgf.cm}^{-2}\right)\end{array}$ & $\begin{array}{c}\text { Tempo de } \\
\text { aquecimento } \\
(\text { minutos })\end{array}$ & $\begin{array}{c}\text { Adição de } \\
\text { água } \\
(\%)\end{array}$ \\
\hline 1 & $5,5-2,5$ & 7,6 & 120,0 & 0,0 \\
2 & $3,5-2,2$ & $7,8-0,0$ & 120,0 & 0,0 \\
3 & $5,0-2,2$ & $7,8-0,0$ & 120,0 & 0,0 \\
\hline
\end{tabular}

cálcio. Os métodos utilizados são apresentados a seguir e os resultados são expressos em termos percentuais em base seca.

\section{Gordura bruta}

A gordura bruta foi determinada pelo método de extração com éter para produtos cárneos, segundo método da AOAC (2000).

\section{Proteina total e proteina digestivel}

Proteína total foi determinada segundo método da AOAC (2000) e proteína digestível, expressa em termos do teor de nitrogênio solúvel, foi determinada pelo método da digestão em pepsina $0,001 \%$, sendo os cálculos realizados segundo AOAC (2000).

\section{Umidade}

A umidade foi determinada de acordo com o método da AOAC (2000).

\section{Cinzas, fósforo e cálcio}

Cinzas, fósforo e cálcio foram determinados pelos métodos AOAC (2000), respectivamente.

\subsection{Análises microbiológicas}

\section{Salmonella sp.}

A análise de Salmonella sp. foi realizada em $25 \mathrm{~g}$ de amostra homogeneizada em $225 \mathrm{~mL}$ de caldo peptonado pré-enriquecido e incubado por 24 horas a $37^{\circ} \mathrm{C}$. Após a incubação, $1 \mathrm{~mL}$ da solução foi transferido para tubos contendo $9 \mathrm{~mL}$ de meio enriquecido seletivo (caldo selenito cistina e caldo tetrationato) e incubado por 24 horas a $37^{\circ} \mathrm{C}$. Após esse período, com o auxílio de uma alça de platina, o material foi transferido para placas contendo meio Ramback. Esta placa foi novamente incubada a $37^{\circ} \mathrm{C}$ por 24 horas, sendo a confirmação realizada pela presença de colônias vermelhas na placa. Para a realização do teste de confirmação para Salmonellas, foi empregado o kit '1-2 Test', fabricado pela Biocontrol/USA, o qual é um método oficial aprovado pela AOAC para a utilização em todos os tipos de alimentos. 


\section{Clostrídios sulfito redutores}

A contagem de clostrídios sulfito redutores (SR) foi realizada em $25 \mathrm{~g}$ de amostra homogeneizada por 60 segundos em stomacher com $225 \mathrm{~mL}$ de solução salina peptonada $0,1 \%$. Foram realizadas diluições de $10^{-1}-10^{-3}$. A partir das diluições, foram semeadas alíquotas de $1 \mathrm{~mL}$ em placas estéreis. Foram adicionados aproximadamente $15 \mathrm{~mL}$ de ágar TSC em temperatura entre $46-48^{\circ} \mathrm{C}$, deixando-se solidificar em superfície plana. $\mathrm{O}$ inóculo foi misturado ao meio de cultura através de movimentos circulares suaves. Após a adição do inóculo, foi transferida uma segunda camada de $10 \mathrm{~mL}$ do mesmo ágar, que foi deixado solidificar-se em superfície plana. Imediatamente após a solidificação do ágar, as placas foram incubadas em câmaras de anaerobiose a $36{ }^{\circ} \mathrm{C}$ por 24 horas. O teste de confirmação foi realizado pelo teste de coloração de Gram. O teste confirmativo de clostrídios sulfito redutores foi realizado transferindo-se o meio de cultura que apresentou contagem anteriormente para um tubo contendo meio de leite tornassolado. Os tubos foram incubados a $36{ }^{\circ} \mathrm{C}$ durante 48 horas. A formação de coágulos, rompidos pela grande quantidade de gás formado, e a acidificação do meio constituem uma prova confirmativa da presença de clostrídios sulfito redutores.

\section{Resultados e discussão}

\subsection{Esterilização em escala piloto}

A Tabela 3 apresenta os resultados referentes a análises físico-químicas realizadas em subprodutos in natura antes e após o processo de esterilização. Pode-se observar que o processo de esterilização/autoclavagem levou ao aumento do percentual final de proteína bruta e proteína digestível nos subprodutos esterilizados nos testes 1,3 e 4 . Este acréscimo foi de 21,9, 18,1 e 24,3\% para proteína bruta e de 25,2, 13,7 e $21,9 \%$ para proteína digestível, respectivamente. Para o teste 2 , ocorreu uma queda de 8,6 e 8,1\% para proteína bruta e proteína digestível, respectivamente. Cabe ressaltar que os baixos teores de proteína encontrados nestes quatro testes estão relacionados com o alto teor de gordura apresentados. O aumento do teor de proteína solúvel pode estar associado à ocorrência de hidrólise parcial das proteínas presentes na matéria-prima, aumentando a digestibilidade.

A Tabela 4 apresenta os resultados referentes às análises microbiológicas realizadas em subprodutos após o processo de esterilização, os quais indicam que o processo de esterilização foi ineficiente para clostrídio SR no teste 3. A contagem de salmonela foi nula para todos os testes em virtude da menor termo-resistência deste microrganismo em relação ao clostrídio SR. No entanto, não foram realizadas provas bioquímicas e sorológicas para certificação da ausência de salmonela.

A Tabela 5 apresenta os resultados das análises físicoquímicas em farinha de subprodutos antes e após a esterilização, além de resultados após a secagem. O processo de secagem foi realizado mantendo a pressão na camisa do esterilizador em $7,5 \mathrm{kgf} . \mathrm{cm}^{-2}$ por um período de 6 horas para todos os testes. Os resultados mostram que a secagem está sendo ineficiente para os testes 1 e 3, ressaltando-se que no teste 3 a farinha alimentada no equipamento já possuía valor de umidade acima do permitido pela legislação (máximo de $8 \%$ ). Os altos teores de cinzas, fósforo e cálcio observados antes do processo de esterilização indicam que as farinhas foram queimadas durante as etapas de processamento na indústria de origem. Quando se analisam os valores de proteína bruta, percebe-se que não houve grandes alterações. Já os teores de proteína digestível sofreram um aumento com o tratamento térmico de 6, 1,7 e 6,6\% para os testes 1, 2 e 3, respectivamente. Este resultado possivelmente se deve à desnaturação e/ou hidrólise sofrida pelas proteínas não digestíveis durante o processamento térmico, o que leva ao aumento da sua digestibilidade.

A Tabela 6 apresenta os resultados referentes às análises microbiológicas realizadas em farinha de subprodutos após o processo de esterilização. Os resultados revelam que o processo de esterilização para farinha de subprodutos foi ineficiente em todos os testes, uma vez que apresentou contagem de clostrídio SR em todas as etapas do processamento. Este comportamento pode estar correlacionado com a termo-resistência dos esporos.

Tabela 3. Análises físico-químicas em subprodutos antes e após o processo de esterilização de subprodutos in natura em escala piloto.

\begin{tabular}{|c|c|c|c|c|c|c|c|}
\hline Testes* $^{*}$ & Umidade & Gordura & $\begin{array}{c}\text { Proteína } \\
\text { bruta }\end{array}$ & $\begin{array}{c}\text { Proteína } \\
\text { digestível }\end{array}$ & Cinzas & Fósforo & Cálcio \\
\hline \multicolumn{8}{|l|}{ Teste 1} \\
\hline Início esterilização & $70,4 \pm 0,2$ & $14,2 \pm 1,8$ & $39,7 \pm 0,1$ & $36,9 \pm 1,0$ & NR & $1,0 \pm 0,1$ & $0,1 \pm 0,1$ \\
\hline Final esterilização & $58,4 \pm 4,3$ & $25,9 \pm 1,6$ & $48,4 \pm 0,4$ & $46,2 \pm 0,4$ & $5,7 \pm 1,1$ & $0,7 \pm 0,1$ & $<0,1$ \\
\hline \multicolumn{8}{|l|}{ Teste 2} \\
\hline Início esterilização & $70,4 \pm 0,2$ & $14,2 \pm 1,8$ & $39,7 \pm 0,1$ & $36,9 \pm 1,0$ & NR & $1,0 \pm 0,1$ & $0,1 \pm 0,1$ \\
\hline Final esterilização & $54,2 \pm 0,2$ & $49,5 \pm 1,6$ & $36,3 \pm 0,4$ & $33,9 \pm 0,2$ & $5,6 \pm 0,1$ & $1,0 \pm 0,1$ & $1,2 \pm 0,1$ \\
\hline \multicolumn{8}{|l|}{ Teste 3} \\
\hline Início esterilização & $70,7 \pm 0,3$ & $17,5 \pm 0,6$ & $44,1 \pm 3,1$ & $42,4 \pm 1,2$ & NR & $0,8 \pm 0,1$ & $0,3 \pm 0,1$ \\
\hline Final esterilização & $59,3 \pm 0,1$ & $21,8 \pm 1,8$ & $52,1 \pm 0,5$ & $48,2 \pm 1,1$ & $15,7 \pm 3,0$ & $0,7 \pm 0,1$ & $3,1 \pm 0,1$ \\
\hline \multicolumn{8}{|l|}{ Teste 4} \\
\hline Início esterilização & $70,7 \pm 0,3$ & $17,5 \pm 0,6$ & $44,1 \pm 3,1$ & $42,4 \pm 1,2$ & NR & $0,8 \pm 0,1$ & $0,3 \pm 0,1$ \\
\hline Final esterilização & $66,8 \pm 3,8$ & $37,3 \pm 2,3$ & $54,8 \pm 3,1$ & $51,7 \pm 0,2$ & $7,0 \pm 0,2$ & $1,9 \pm 0,1$ & $5,7 \pm 0,1$ \\
\hline
\end{tabular}

${ }^{\star}$ Os resultados das análises estão expressos em termos percentuais considerando base seca. 
Segundo Juneja et al. (2003), as altas temperaturas de estocagem e o longo tempo de exposição ao calor durante a cocção da farinha podem aumentar a termo-resistência de Clostridium perfringens.

Apesar do processo de esterilização ter sido mais eficiente nos subprodutos in natura, optou-se por realizar testes em escala industrial somente com a farinha de subprodutos. Entre as razões que motivaram tal escolha está o fato de haver agregação de água, diluindo o subproduto. Como o processo a vapor apresenta capacidade calorífica elevada, seria necessário muito tempo para ocorrer a secagem da farinha até os limites especificados pela legislação vigente. Além disso, este subproduto esterilizado teria de ser submetido a mais dois tratamentos térmicos: um durante o processo de digestão e outro durante o processo de secagem. Todos esses tratamentos térmicos acarretariam perdas na qualidade nutricional da farinha por aumentar o teor de cinzas e diminuir o teor de proteína digestível, causadas pela desnaturação proteica.

Tabela 4. Análises microbiológicas em subprodutos após o processo de esterilização em escala piloto.

\begin{tabular}{lcc}
\hline \multicolumn{1}{c}{ Testes } & Salmonella & Clostridium SR \\
\hline Teste 1 & & \\
Início da esterilização & NR & NR \\
Final da esterilização & Ausente & Ausente \\
Teste 2 & & \\
Início da esterilização & NR & NR \\
Final da esterilização & Ausente & Ausente \\
Teste 3 & & \\
Início da esterilização & NR & NR \\
Final da esterilização & Ausente & $2,4 \times 10^{3}$ \\
Teste 4 & & \\
Início da esterilização & NR & NR \\
Final da esterilização & Ausente & Ausente \\
\hline
\end{tabular}

$\mathrm{NR}=$ Análise não realizada.

\subsection{Esterilização em escala industrial}

A Tabela 7 apresenta os resultados das análises físicoquímicas realizadas na farinha de subprodutos durante as etapas de processamento. A secagem da farinha foi realizada por 2 horas, mantendo uma pressão na camisa de $7,8 \mathrm{kgf.cm}^{-2}$ e no eixo e pás de 3,5 kgf.cm ${ }^{-2}$. Os resultados referentes ao teor de umidade após o processo de esterilização indicam que não há a necessidade da realização do processo secagem, uma vez que os valores obtidos encontram-se bem abaixo do máximo permitido pela legislação e o processo de esterilização está agregando pouca água ao produto final. Este resultado é importante do ponto de vista de viabilidade técnica e econômica, uma vez que há a possibilidade de se eliminar um tratamento térmico do processo. Outro aspecto a ser considerado diz respeito à qualidade final da farinha. Como a farinha já apresenta um teor de cinzas elevado mesmo antes da esterilização, a eliminação do processo de secagem permite que esses teores não aumentem ainda mais, mantendo a qualidade. Com relação às proteínas da farinha, há a possibilidade do tratamento térmico desnaturá-las.

Os valores para gordura, cinzas, cálcio e fósforo estão muito elevados em todos os casos, mesmo para a farinha antes da esterilização (Tabela 7). O resultado mais expressivo obtido durante o processo de esterilização está relacionado com a manutenção do teor de proteína bruta e aumento do teor de proteína digestível em 3,2, 9,3 e 6,3\% para os testes 1,2 e 3 , respectivamente. A partir dos dados do teor de proteína bruta e digestível é possível determinar a digestibilidade da farinha. Neste trabalho, a digestibilidade obtida foi de $89,1,93,4$ e $93,2 \%$ para os testes 1, 2 e 3, respectivamente. Suzuki et al. (2006) mostram que há a possibilidade de degradação de proteínas insolúveis pela ação de microrganismos termofílicos na farinha. Como consequência, tem-se um aumento no teor de proteína na farinha. Esta constatação explica em parte os resultados obtidos nesse trabalho, em que o teor de proteína foi superior aos iniciais na maioria dos ensaios.

Shirley e Parsons (2001) avaliaram a influência do teor de cinzas na composição de aminoácidos e a digestibilidade em amostras de farinha de carne e ossos. Entre os resultados obtidos

Tabela 5. Análises físico-químicas em farinha de subprodutos antes e após o processo de esterilização em escala piloto.

\begin{tabular}{|c|c|c|c|c|c|c|c|}
\hline Testes $^{*}$ & Umidade & Gordura & $\begin{array}{c}\text { Proteína } \\
\text { bruta }\end{array}$ & $\begin{array}{c}\text { Proteína } \\
\text { digestível }\end{array}$ & Cinzas & Fósforo & Cálcio \\
\hline \multicolumn{8}{|l|}{ Teste 1} \\
\hline Início esterilização & $3,7 \pm 0,1$ & $13,5 \pm 0,1$ & $63,6 \pm 0,4$ & $56,9 \pm 0,1$ & $16,4 \pm 0,1$ & $3,0 \pm 0,1$ & $4,6 \pm 0,1$ \\
\hline Após secagem & $20,8 \pm 0,1$ & $16,5 \pm 0,1$ & $64,0 \pm 0,5$ & $60,3 \pm 0,1$ & $14,5 \pm 0,1$ & $2,3 \pm 0,1$ & $3,1 \pm 0,1$ \\
\hline \multicolumn{8}{|l|}{ Teste 2} \\
\hline Após secagem & $6,5 \pm 0,1$ & $13,6 \pm 0,1$ & $65,4 \pm 1,1$ & $60,5 \pm 0,1$ & $15,5 \pm 0,1$ & $2,6 \pm 0,1$ & $4,0 \pm 0,1$ \\
\hline \multicolumn{8}{|l|}{ Teste 3} \\
\hline Início esterilização & $19,1 \pm 0,2$ & $14,2 \pm 0,1$ & $63,3 \pm 0,3$ & $57,9 \pm 0,1$ & $15,6 \pm 0,1$ & $2,7 \pm 0,1$ & $3,7 \pm 0,1$ \\
\hline Final esterilização & $25,8 \pm 0,3$ & $13,1 \pm 0,1$ & $66,3 \pm 0,5$ & $62,6 \pm 0,1$ & $16,8 \pm 0,1$ & $2,9 \pm 0,1$ & $4,7 \pm 0,1$ \\
\hline Após secagem & $12,5 \pm 0,4$ & $14,0 \pm 0,1$ & $65,9 \pm 0,4$ & $61,7 \pm 0,1$ & $16,5 \pm 0,1$ & $2,8 \pm 0,1$ & $4,0 \pm 0,1$ \\
\hline
\end{tabular}

${ }^{\star}$ Os resultados das análises estão expressos em termos percentuais considerando base seca. 
destaca-se o fato de que a redução no teor e qualidade da farinha, quando o teor de cinzas aumenta, é quase totalmente devido ao decréscimo na quantidade de aminoácidos por unidade, não na digestibilidade dos aminoácidos. Neste trabalho, apesar da

Tabela 6. Análises microbiológicas em farinha de subprodutos após a esterilização em escala piloto.

\begin{tabular}{llc}
\hline \multicolumn{1}{c}{ Amostra } & Salmonella & Clostridium SR \\
\hline Teste 1 & & \\
Início da esterilização & Ausente & $4,5 \times 10^{2}$ \\
Final da esterilização & Ausente & $2,0 \times 10^{2}$ \\
Após secagem & Ausente & $8,0 \times 10^{1}$ \\
Teste 2 & & \\
Início da esterilização & Ausente & $4,5 \times 10^{1}$ \\
Final da esterilização & Ausente & $6,0 \times 10^{2}$ \\
Após secagem & Ausente & $1,5 \times 10^{2}$ \\
Teste 3 & & \\
Início da esterilização & Ausente & $2,1 \times 10^{2}$ \\
Final da esterilização & Ausente & $1,3 \times 10^{2}$ \\
Após secagem & Ausente & $3,0 \times 10^{1}$ \\
\hline
\end{tabular}

concentração de cinzas variar entre 5-20\%, esta variável não apresentou influência negativa na digestibilidade da farinha.

A Tabela 8 apresenta os resultados das análises microbiológicas nos testes realizados em escala industrial com farinha de subprodutos. O processo de esterilização foi eficiente para todos os testes 1 e 3 , mostrando que o esterilizador empregado pode ser usado para a obtenção de farinhas de subprodutos com padrões microbiológicos e nutricionais. Apesar do teste 2 apresentar contagem de clostrídio SR, o esterilizador industrial apresentou um bom desempenho comparado com o piloto, uma vez que sua capacidade de carga é cerca de 20 vezes maior. Este resultado pode ser atribuído ao fato de que o esterilizador industrial apresenta sistema de agitação e injeção de vapor no eixo e nas pás, o que melhora a eficiência do processo de transferência de calor no meio.

\section{Conclusões}

Neste trabalho, foi investigada qual a melhor estratégia de esterilização/autoclavagem da farinha de subprodutos animais, visando a obtenção de uma farinha com elevado valor nutricional e com padrões higiênico-sanitários aceitáveis.

Tabela 7. Análises físico-químicas em farinha de subprodutos antes e após o processo de esterilização no esterilizador industrial.

\begin{tabular}{|c|c|c|c|c|c|c|c|}
\hline Testes & Umidade & Gordura & $\begin{array}{c}\text { Proteína } \\
\text { bruta }\end{array}$ & $\begin{array}{c}\text { Proteína } \\
\text { digestível }\end{array}$ & Cinzas & Fósforo & Cálcio \\
\hline \multicolumn{8}{|l|}{ Teste 1} \\
\hline Início esterilização & $3,4 \pm 0,1$ & $15,0 \pm 0,1$ & $66,8 \pm 1,2$ & $58,5 \pm 0,6$ & $18,0 \pm 0,5$ & $2,5 \pm 0,1$ & $5,5 \pm 0,2$ \\
\hline Final esterilização & $3,7 \pm 0,1$ & $14,7 \pm 0,1$ & $67,3 \pm 1,2$ & $60,8 \pm 1,1$ & $18,5 \pm 0,1$ & $3,2 \pm 0,1$ & $5,8 \pm 0,1$ \\
\hline Após secagem & $0,2 \pm 0,1$ & $14,9 \pm 0,1$ & $67,8 \pm 0,1$ & $60,4 \pm 0,4$ & $18,8 \pm 0,1$ & $3,2 \pm 0,1$ & $5,7 \pm 0,1$ \\
\hline \multicolumn{8}{|l|}{ Teste 2} \\
\hline Início esterilização & $4,1 \pm 0,1$ & $22,0 \pm 0,1$ & $59,2 \pm 1,0$ & $52,7 \pm 0,6$ & $14,4 \pm 0,2$ & $2,5 \pm 0,1$ & $4,3 \pm 0,3$ \\
\hline Final esterilização & $6,9 \pm 0,1$ & $19,9 \pm 0,9$ & $62,9 \pm 2,9$ & $58,4 \pm 0,6$ & $14,9 \pm 0,1$ & $2,8 \pm 0,1$ & $4,9 \pm 0,2$ \\
\hline Após secagem & $1,5 \pm 0,1$ & $19,4 \pm 0,1$ & $61,5 \pm 1,2$ & $57,6 \pm 0,7$ & $16,4 \pm 0,3$ & $2,9 \pm 0,2$ & $5,1 \pm 0,3$ \\
\hline \multicolumn{8}{|l|}{ Teste 3} \\
\hline Início esterilização & $3,2 \pm 0,1$ & $22,5 \pm 0,4$ & $59,8 \pm 0,2$ & $54,1 \pm 0,3$ & $15,7 \pm 0,2$ & $2,7 \pm 0,1$ & $4,9 \pm 0,3$ \\
\hline Final esterilização & $5,4 \pm 0,1$ & $18,0 \pm 0,1$ & $62,4 \pm 1,2$ & $58,2 \pm 0,3$ & $17,4 \pm 0,1$ & $2,7 \pm 0,1$ & $5,5 \pm 0,1$ \\
\hline Após secagem & $0,9 \pm 0,1$ & $17,8 \pm 0,6$ & $61,7 \pm 0,1$ & $57,5 \pm 0,9$ & $17,6 \pm 0,2$ & $2,9 \pm 0,1$ & $5,1 \pm 0,2$ \\
\hline
\end{tabular}

${ }^{*}$ Os resultados das análises estão expressos em termos percentuais considerando base seca.

Tabela 8. Análises microbiológicas em farinha de subprodutos após o processo de esterilização em esterilizador industrial.

\begin{tabular}{llc}
\hline \multicolumn{1}{c}{ Teste } & Salmonella & Clostridium SR \\
\hline Teste 1 & & Ausente \\
Início da esterilização & Ausente & Ausente \\
Final da esterilização & Ausente & Ausente \\
Após secagem & Ausente & $5,0 \times 10^{1}$ \\
Teste 2 & & $9,8 \times 10^{1}$ \\
Início da esterilização & Ausente & $3,0 \times 10^{1}$ \\
Final da esterilização & Ausente & \\
Após secagem & Ausente & Ausente \\
Teste 3 & & Ausente \\
Início da esterilização & Ausente & Ausente \\
Final da esterilização & Ausente & Ausente \\
Após secagem & & \\
\hline
\end{tabular}


Os resultados mostraram que a melhor estratégia é realizar o processo de esterilização na farinha de subprodutos, ao invés do subproduto in natura. A agregação de água durante o processo de esterilização de subprodutos in natura requer a exposição prolongada sob altas temperaturas durante a secagem do produto, o que compromete sua qualidade nutricional. Paralelamente, foram realizados testes de esterilização em escala piloto e industrial.

Os resultados obtidos na esterilização em escala piloto apresentaram a tendência de aumento da concentração de proteína bruta e digestível, melhorando a qualidade nutricional da farinha. No entanto, o processo foi ineficiente na eliminação de microrganismos, detectando-se a presença de clostrídio SR em todos os testes realizados com farinha de subprodutos. Para o processo de esterilização em escala industrial, o teor de proteína aumentou em todos os testes e a digestibilidade final da farinha foi de aproximadamente $92 \%$, o que eleva seu valor de mercado. Com relação à eliminação de microrganismos, o processo foi eficiente em dois dos três testes realizados.

\section{Referências bibliográficas}

ASSOCIATION OF OFFICIAL ANALYTICAL CHEMISTS - AOAC. Official Methods of Analysis of AOAC International. 17 ed. Gaithersburg, 2000.
BELLAVER, C. Limitações e vantagens do uso de farinhas de origem animal na alimentação de suínos e de aves. In: SIMPÓSIO BRASILEIRO DA INDÚSTRIA DE ALIMENTAÇÃO ANIMAL, 2, 2005, Curitiba. Anais...

BRASIL. Ministério da Agricultura e Abastecimento. Sindicato Nacional da Indústria de Alimentação Animal. Associação Nacional dos Fabricantes de Rações. Compêndio brasileiro de alimentação animal. São Paulo: ANFAR/CBNA/SDR, 2005.

JUNEJA, V. K. et al. Increased thermotolerance of Clostridium perfringens spores following sublethal heat shock. Food Control, v. 14, n. 3, p. 163-168, 2003.

MANN, I. Processing and utilization of animal by-products. Roma: FAO, 1962.

MINISTÉRIO DA AGRICULTURA, PECUÁRIA E ABASTECIMENTO - MAPA. Instrução Normativa $N^{\circ} 15$. Brasília, 2003. Disponível em: $<$ www.agricultura.gov.br>. Acesso em: Outubro 2009.

RITTNER, H. Tecnologia das matérias graxas. São Paulo: Ed. Triângulo, 2001. (v. 1).

SHIRLEY, R. B.; PARSONS, C. M. Effect of ash content on protein quality of meat and bone meal. Poultry Science, v. 80, n. 5, p. 626-632, 2001.

SUZUKI, Y. et al. Decomposition of extremely hard-to-degrade animal proteins by thermophilic bacteria. Journal of Bioscience and Bioengineering, v. 102, n. 2, p. 73-81, 2006. 